\title{
Archipelago-wide coral recovery patterns since 1998 in the Chagos Archipelago, central Indian Ocean
}

\author{
C. R. C. Sheppard*, A. Harris, A. L. S. Sheppard \\ Department of Biological Sciences, University of Warwick, Coventry CV4 7AL, UK
}

\begin{abstract}
Patterns of coral recovery are analysed across reefs of the Chagos Archipelago, which spans $400 \times 250 \mathrm{~km}$ in the central Indian Ocean. This archipelago mostly lacks direct human impacts and is subject only to global changes such as a rise in sea surface temperature. Following very heavy coral mortality (mostly $>90 \%$ ) caused by the 1998 warming event, and despite 2 further sub-lethal bleaching events, the recovery of coral cover, colony numbers and juvenile recruitment has been good in many parts of the archipelago. There was little discrimination between atolls and depths, with a notable exception of 1 atoll where a repeat of heavy mortality had occurred in 2005. In 2006, coral cover was almost restored to pre-1998 values at most shallow sites, but had recovered much less in deeper waters. However, in shallow water, coral cover values alone are a poor indication of recovery, because present, shallow cover mainly comes from Acropora palifera and other corals that are largely encrusting in juvenile form, in contrast to their mature condition, in which they provide a 3-dimensional 'forest' structure. Recruitment of juvenile colonies in 2006 ranged from 6 to $28 \mathrm{~m}^{-2}$. Total juvenile density showed no significant pattern with atolls or with depth, but, taking each genus of juveniles in turn, many genera showed a marked depth preference. No shift was observed towards algal domination, or to assemblages dominated by Porites or faviids, as has been reported elsewhere. Recovery in Chagos $8 \mathrm{yr}$ after massive coral and soft coral mortality is discussed in relation to an absence of other, locally manageable factors such as pollution, over-fishing and sedimentation.
\end{abstract}

KEY WORDS: Coral reef $\cdot$ Coral bleaching $\cdot$ Recovery $\cdot$ Sea surface temperature

\section{INTRODUCTION}

Much has been written about the substantial loss of corals and reefs following the 1998 seawater warming (see Wilkinson 2004 for summary). Estimations of amounts and rates of subsequent recovery are important both to predictions of future reef condition and to management of protected areas (McClanahan 2007), but so far there is much less information on recovery, particularly at the scale of whole reef systems.

Deterioration of most reefs clearly began decades ago from over-fishing, disease, crown-of-thorns starfish Acanthaster planci outbreaks, pollution and other natural reasons such as hurricanes (e.g. Jackson 1997, Jackson et al. 2001, Pandolfi et al. 2003, Roberts 2007).
Even so, only a decade ago, Connell (1997) could say that of 65 sets of coral data examined, $58 \%$ had stable communities, and, of those which had suffered decline, many had subsequently recovered. Since the 1998 mass mortality, more attention has been focussed on long-term, global changes. Declines reported more recently (Gardner et al. 2003, Bruno \& Selig 2007) have led to debate concerning the ability of reefs to recover, whether many settle into some form of 'alternative stable state' (Knowlton 1992), or where, exactly, along any particular declining trajectory, there may be a point beyond which recovery is irreversible.

The Indian Ocean was the worst affected by the 1998 warming episode (Wilkinson 2004). Remote islands and archipelagos were especially vulnerable, contrary 


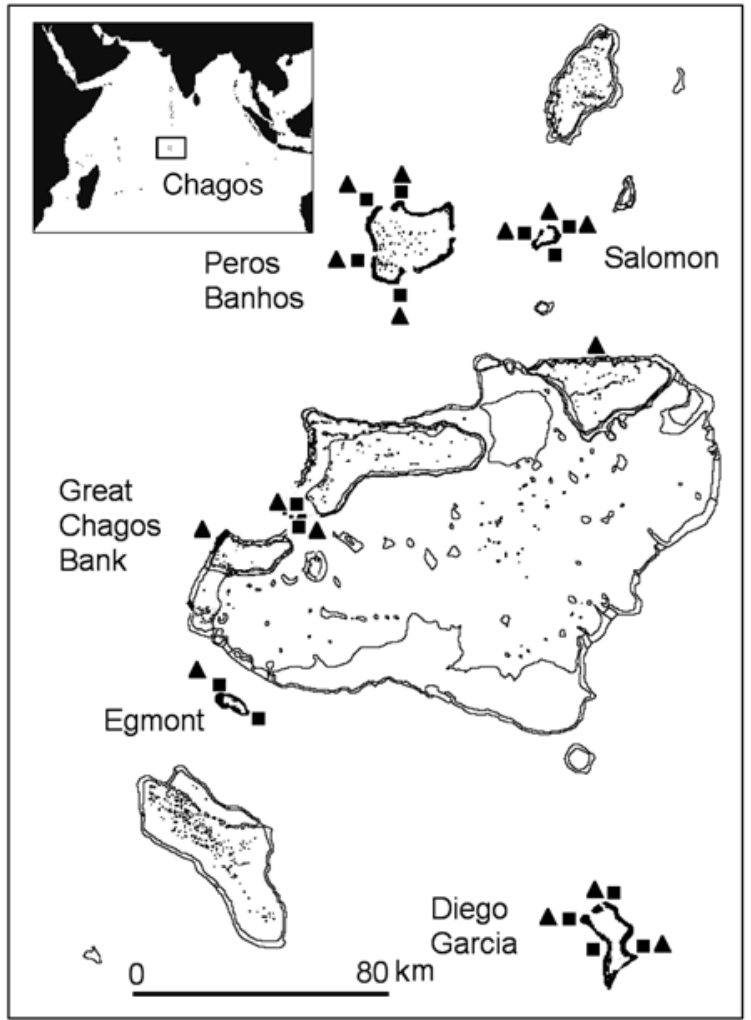

Fig. 1. Location and map of the Chagos Archipelago. घ: sites sampled for $\mathrm{N}$ and percent cover; $\mathbf{\Delta}$ : sites of juvenile coral counts

to previous predictions which had assumed that remoteness from direct human impacts afforded protection (Bryant et al. 1998). The very remote Chagos Archipelago (Fig. 1) was particularly badly affected, suffering total or very heavy coral mortality on seaward slopes to $>30 \mathrm{~m}$ depth (depending on the atoll), with species-specific mortality extending deeper still (Sheppard et al. 2002). Cover values of coral and soft coral on seaward slopes before 1998 totalled 50 to $95 \%$, which declined in 1998 to an average of $12 \%$, and even to zero between 0 and $5 \mathrm{~m}$ depth in some shallow areas (Sheppard 1999a). Such massive impact, and forecast trends of further water warming and acidification, have led to several very gloomy prognoses for the future of reefs (Hoegh-Guldberg 1999, Sheppard 2003, Hoegh-Guldberg et al. 2007).

Initial mortality of benthic coelenterates was followed by a collapse of the reefs' architectural structure, which brought with it, firstly, some selective losses of obligate corallivores (Spalding \& Jarvis 2002) followed after a few years by substantial changes in many fish populations (Graham et al. 2006). On many reefs, algal abundance increased substantially too (Rogers \& Miller 2006).
In Chagos, no algal increase followed the coral mortality, so that substantial areas of rocky substrate remained essentially uncolonised by macro-organisms for at least 3 yr (Sheppard et al. 2002). By 2001, new coral recruitment on old rock, newly dead coral colonies and unconsolidated rubble was substantial to a depth of $30 \mathrm{~m}$.

In the present study, we measure the degree of coral recovery on seaward reefs across the Chagos Archipelago. This location mostly lacks reef fishing, shoreline construction, sediment disturbance, or local pollution (Guitart et al. 2007), which therefore do not confound recovery from the warming-induced mortality. However, repeated, though less severe, bleaching and associated mortality events have been observed throughout the archipelago in intervening years (C. R. C. Sheppard unpubl. data), in common with similar repeats of warming episodes in adjacent regions such as the central Maldives (C. Anderson pers. comm.), Oman and the Straits of Hormuz in both 2002 and 2004 (Wilson et al. 2002), Rodrigues in 2002 and later (Hardman et al. 2004), the Seychelles (Sheppard et al. 2005) and Mauritius in 2003 (Turner \& Klaus 2005). Several further instances of moderate bleaching in this ocean are reported in Wilkinson (2004), who notes varying degrees of severity from India to Africa, with some island groups being apparently more affected than several mainland areas. Thus, any recovery must be examined in the context of repeated but lesser warming events rather than as a simple succession from a single severe impact.

\section{METHODS}

Sampling sites. Seaward slopes of all 5 islanded atolls of the Chagos Archipelago (Fig. 1) were investigated from February to March 2006. We used a nested sampling design of 5 atolls, studying a total of 18 sites around the atolls, and up to 5 depths at each site (at 5, $10,15,20$ and $25 \mathrm{~m}$ ), with a varying number of replicates at each depth. Coral cover and numbers of colonies $>5 \mathrm{~mm}$ diameter were estimated in quadrats at all 5 depths, with additional counts of new recruits at 5, 15 and $25 \mathrm{~m}$ depth.

As many sites as possible needed to be studied across all 5 atolls. Thus, 440 quadrats $(0.5 \times 0.5 \mathrm{~m})$ were examined on transects placed along depth contours on seaward slopes. In each quadrat, the number $(\mathrm{N})$ of all coral colonies $>5 \mathrm{~mm}$ were counted. Secondly, an estimate was made by eye of total coral cover in each quadrat. Eye estimation followed AIMS protocols, with the differences that estimates were made in the quadrats rather than across large reef areas, as is common, for example, with manta tows, and, secondly, 
finer divisions of percent cover were made than specified for values $<10 \%$ or $>75 \%$ coral cover. Quadrats were laid randomly along the depth contours. Colonies counted included those which partly extended outside the quadrats.

Data on the number of colonies and percent cover were strongly nonnormal after all common transformations, precluding ANOVA. Therefore, nonparametric methods were used (Primer v6; Clarke \& Gorley 2006), mainly the ANOSIM (analysis of similarity) routines. Simple standardisation procedures were used to account for different numbers of quadrats at different sites, and Primer's 'normalisation' procedure was used to give equal weight to $\mathrm{N}$ and cover values prior to creating Bray-Curtis similarity matrices.

A second set of measurements of juvenile colonies at 5, 15 and $25 \mathrm{~m}$ depth recorded size and genus of colonies within an additional 1159 randomly placed $0.11 \mathrm{~m}^{2}(33 \times 33 \mathrm{~cm})$ quadrats. Up to 46 replicates were recorded at each site. Juveniles were recorded in $10 \mathrm{~mm}$ size categories from 0 to $100 \mathrm{~mm}$, measured as total distance across the surface of each colony along the longest axis. A further 2603 hard coral juveniles from 35 genera were recorded in a total sampling area of $129 \mathrm{~m}^{2}$. ANOSIM and $\chi^{2}$ were used to test for distribution patterns with depth.

Sea temperature data. HadISST1 sea surface temperature (SST) data were used to obtain SST patterns for Chagos (Rayner et al. 2003); this is monthly, with a spatial resolution of $1^{\circ}$ latitude and longitude. Chagos is covered by a $3 \times 3$ grid, so the average of the 9 cells was used to illustrate the broad temperature pattern in the region as a whole.

\section{RESULTS}

\section{Seawater temperature}

Monthly SST values for the Chagos region from 1980 to 2006 (Fig. 2) show the large warming spike in 1998, as well as more recent spikes, which, in Chagos, also caused extensive bleaching (C. R. C. Sheppard unpubl. data), though subsequent mortality was minor at all observed sites except at Egmont atoll (see 'Egmont atoll repeat mortality'). Warming is neither smooth nor continuous; however, it shows a 3 to 5 yr cycle, which may result from a combined influence of the Indian Ocean Dipole and the El Niño-Southern Oscillation
(ENSO) (Purkis \& Riegl 2005). The 12 mo monthly running mean of the SST data (see Fig. 2) similarly shows that this cycle in Chagos is about 0.4 to $0.8^{\circ} \mathrm{C}$, enough to trigger bleaching (Hoegh-Guldberg 1999). Coral recovery must therefore be considered against the background of a repeat in high temperature events sufficient to cause physiological stress to corals.

\section{Coral recovery}

Eight years after the very heavy mortality, overall recovery patterns were variable over the archipelago (Fig. 3). There was no significant correlation between $\mathrm{N}$ and percent cover $(\mathrm{r}=0.041, \mathrm{p}=0.390)$, with quadrats containing $100 \%$ cover by 1 or 2 colonies (usually Acropora tables), to a maximum of 36 colonies in 1 quadrat at $10 \mathrm{~m}$ depth. Most conspicuous was the recovery of cover of $A$. palifera in the shallowest zone ( 0 to $5 \mathrm{~m}$ depth) and of tabular A. cytherea at some sites between 4 and $10 \mathrm{~m}$ depth; both species had been virtually eliminated in 1998. Patchiness within this average is marked, and, overall, there was no marked pattern of change in either cover or total colony density with depth. The one exception was the continued very low cover at several sites on the Egmont atoll (see 'Egmont atoll repeat mortality'). Much evidence remained of old, dead colonies, especially in shallow water, which may reflect further interruptions to recovery in the earlier 2000s as well as being a legacy from 1998.

Frequency diagrams (Fig. 4) show the variability (across atolls and depths) in the frequencies of values 

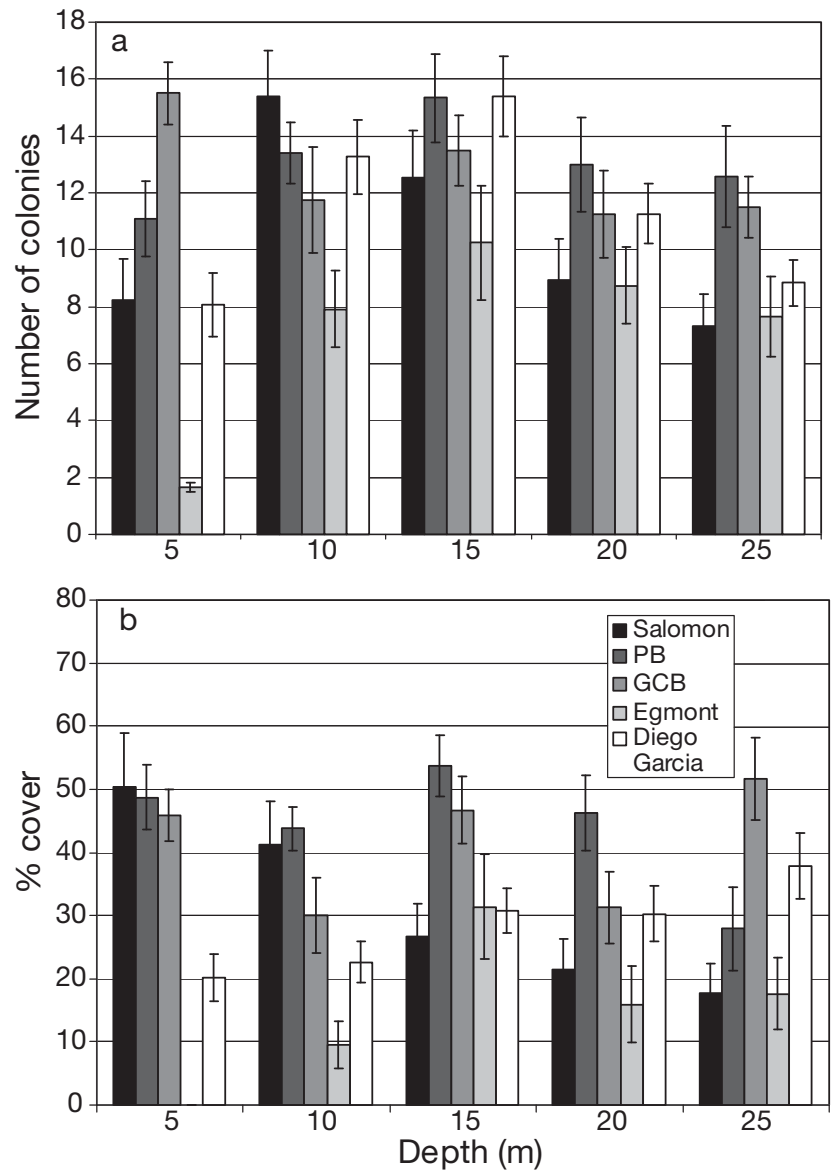

Fig. 3. (a) Number of colonies per quadrat and (b) percent coral cover, measured in the quadrats, at each depth on each atoll. Error bars show mean \pm SE. PB: Peros Banhos; GCB: Great Chagos Bank

of colonies and of percent cover in the 440 quadrats. There is considerable variability in lower frequencies, at which different values of $\mathrm{N}$ occurred (Fig. 4a,c), across both atolls and depths. Coral cover (Fig. 4b,d) was much more consistent across both atolls and depths. Low cover values of $<20 \%$ were frequent at 3 atolls and all depths. The patterns suggest that some depths (shallow) and atolls (Egmont and Peros Banhos to a lesser extent) show greater variability or different patterns to the others, emphasising the patchiness in the extent to which sites recover considering these 2 measures.

A 2-way crossed ANOSIM (Clarke \& Gorley 2006) on colony count $(\mathrm{N})$ and coral cover (factors are 5 atolls and 5 depths) showed that differences between atolls (across all depths) and between depths (across all atolls) (Table 1) were strongly significant globally $(\mathrm{R}=$ $0.057, \mathrm{p}=0.001 ; \mathrm{R}=0.06, \mathrm{p}=0.001$, respectively). Pairwise results showed that all pairings involving Egmont atoll had consistently much higher global R-values than pairings without Egmont atoll. Global differences
Table 1. ANOSIM crossed, 2-way probability values of percent coral cover, using the 5 atolls and 5 depth zones on each. Atoll and depth are factors. Every atoll and every depth in turn was then excluded from ANOSIM runs. Values in bold show the only omission of all of the combinations (Egmont atoll) that produced $\mathrm{p}>0.01$

\begin{tabular}{|c|c|c|}
\hline & All sites & $\begin{array}{l}\text { Without Egmont } \\
\text { atoll }\end{array}$ \\
\hline $\begin{array}{l}\text { Between atoll groups } \\
\text { (across all depths) }\end{array}$ & $\begin{array}{l}R=0.057 \\
p=0.001\end{array}$ & $\begin{array}{l}R=0.003 \\
p=0.42\end{array}$ \\
\hline $\begin{array}{l}\text { Between depths } \\
\text { (across all atolls) }\end{array}$ & $\begin{array}{l}\mathrm{R}=0.06 \\
\mathrm{p}=0.001\end{array}$ & $\begin{array}{l}R=0.059 \\
p=0.001\end{array}$ \\
\hline
\end{tabular}

were re-examined after removing data for each depth and then each atoll in turn: differences remained strongly significant after removing data for each depth in turn, but when data for each atoll were removed, the removal of Egmont atoll (and only Egmont) from the ANOSIM test showed no difference between the remaining atolls $(\mathrm{R}=0.003, \mathrm{p}=0.42)$ (Table 1 , righthand column). Egmont atoll as a whole, therefore, was strikingly different, and, from Fig. 4, this can be seen to apply to both cover and $N$. Interestingly, the partially militarised atoll of Diego Garcia had a pattern of $\mathrm{N}$ and cover that was not different from the uninhabited atolls, except Egmont.

Coral cover with depth in 2006 can be compared with mean values collected from quadrats or line transects from both 1978 and shortly after mortality in 2001. Data from the 2 northern atolls (Fig. 5) are used, as these are the locations examined on all 3 dates. Recovery of coral cover was greatest in shallow water, where it appeared to be approaching values seen $30 \mathrm{yr}$ ago. In deeper water, recovery was substantially less and, deeper than approximately 20 to $25 \mathrm{~m}$, it still resembled immediate post-mortality values. Below $25 \mathrm{~m}$, coral cover in 2004 appeared considerably greater (but was not measured).

\section{Juvenile colonies}

The number of juveniles was counted in 2006 (Table 2) and compared with numbers counted in 2001. Overall juvenile density in 2006 averaged $23.3 \mathrm{~m}^{-2}$, with a range of 6 juveniles $\mathrm{m}^{-2}$ at Egmont $(5 \mathrm{~m})$ to 28 juveniles $\mathrm{m}^{-2}$ at Salomon atoll (15 m). The 2006 density is lower than in 2001, but numbers must be qualified by 2 factors. Firstly, the defined size of 'juvenile' was larger in 2001. Secondly, only 2 yr after the mass mortality, cover by coelenterates was only about a quarter of that seen in 2006, leaving much more unoccupied substrate available to planulae. If this greater available 

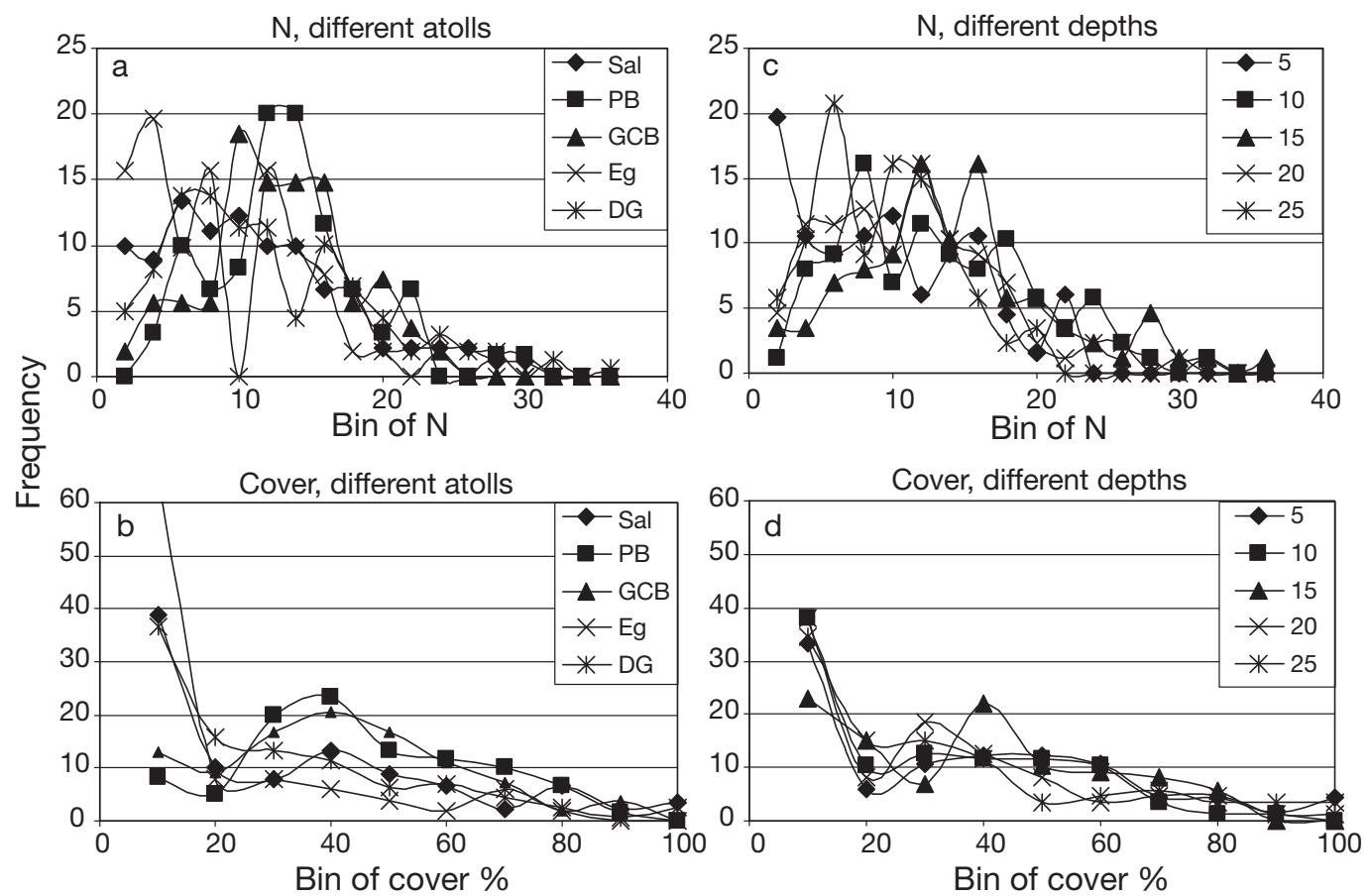

Fig. $4(\mathrm{a}, \mathrm{c})$ Number of colonies $(\mathrm{N})$ and $(\mathrm{b}, \mathrm{d})$ coral cover for the different atolls and different depths. Bins for $\mathrm{N}$ in each quadratare in intervals of 2. Bins for percent cover in the quadrats are in intervals of $10 \%$. Sal: Salomon; PB: Peros Banhos; GCB: Great Chagos Bank; Eg: Egmont; DG: Diego Garcia

space is taken into account, then juvenile density in the 2 yr is more similar (Table 2). There are no data on juveniles from before the 1998 mortality.

Total juvenile numbers are abundant. The main difference noted in 2001 was that Great Chagos Bank had only about half the number of juveniles than all other atolls (Sheppard et al. 2002), but, by 2006, this difference had disappeared.

The generic identity of juveniles was distinguished in both 2001 and 2006. The most abundant are shown

Table 2. Density of juveniles and percent of bare substrate potentially available for juveniles in 2001 and 2006 (data for 2001 from Sheppard et al. 2002 and S. Wilson unpubl. data). The mean value of $23.2 \mathrm{~m}^{-2}$ in 2006 is the average for the 36 atoll/depth combinations. 'Adjusted' mean number takes into account the greater potential space for settlement in the earlier year

\begin{tabular}{|lcc|}
\hline & 2001 & 2006 \\
\hline Size of juvenile & $2-160 \mathrm{~mm}$ & $0-100 \mathrm{~mm}$ \\
Mean juveniles $\mathrm{m}^{-2}$ & 65.8 (SD 52) & 23.2 (range 6-28) \\
\% coral cover & 12.3 (SD 10.9) & 31.7 (SD 25) \\
\% soft coral cover & Trace & 13.6 (SD 15) \\
\% coral + soft coral & $\sim 13$ & 45.4 \\
\% not covered by coral & 87 & 54.6 \\
$\begin{array}{l}\text { and soft coral } \\
\text { 'Adjusted' mean number } \\
\text { of juveniles }\end{array}$ & 75 & 42 \\
\hline
\end{tabular}

in Table 3. In 2001, Acropora juveniles were dominant, which in 2006 is reflected in the high cover at some sites of adult $A$. cytherea and $A$. palifera. This was followed by Montipora, Pavona and several faviids, mainly Favia and Favites. The same groups dominated again in 2006, but Acropora was proportionately less prevalent because of a marked increase of Pavona var-

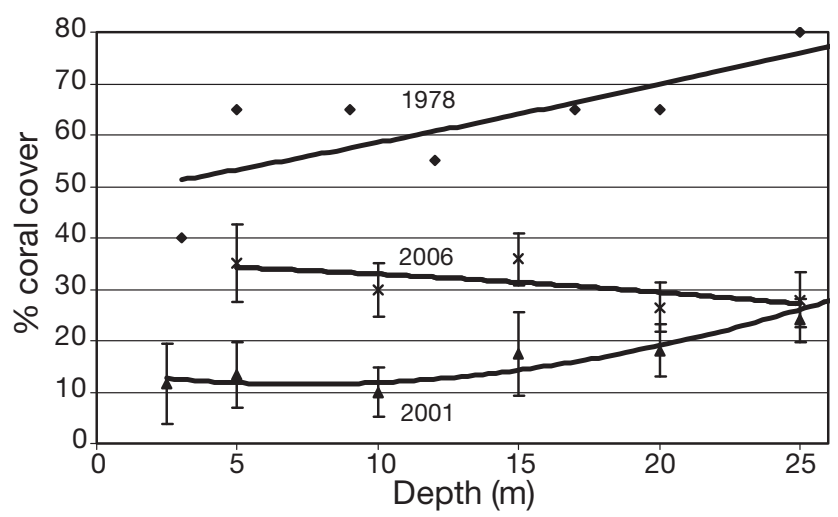

Fig. 5. Coral cover with depth (second-order polynomial lines of best fit) at the 2 northern Chagos atolls where data exist for 1978, 2001 and 2006. Measurements for each year were taken from the same locations and depths. Error bars on the 2001 and 2006 curves are $95 \%$ CI limits. Data to obtain CI or error bars for 1978 were lost; $\$$ : mean values for the different depths in 1978. Data for 1978 and 2001 are from Sheppard (1980), Sheppard et al. (2002) and C. R. C. Sheppard (unpubl. data) 
ians juveniles. Montipora, which had been second in numerical importance $3 \mathrm{yr}$ after the mortality event, was considerably reduced in 2006. Densities of faviids and Porites were similar on both dates.

The number of total recruits showed no differences in average density between depths or atolls. However, when generic information is included, a 2-way crossed ANOSIM testing (unreplicated) for differences in coral juvenile genera (pooled data for each depth at each atoll) shows significant differences between depths $(\mathrm{R}=0.75, \mathrm{p}=0.049)$, but not between atolls $(\mathrm{R}=0.122$, $\mathrm{p}=0.31$ ).

The genera driving these global depth differences were determined by $\chi^{2}$ tests; the number of recruits of each genus was tested against the null hypothesis of no difference with depth (Table 4). Thirteen genera showed clear depth preferences. Many genera were encountered too infrequently to achieve the $\chi^{2}$ validity requirement of no more than $20 \%$ of expected frequencies being $<5$, though an additional 5 genera showed $>5$-fold differences between depths, and these are also noted in the final column of Table 4 . Since recruitment
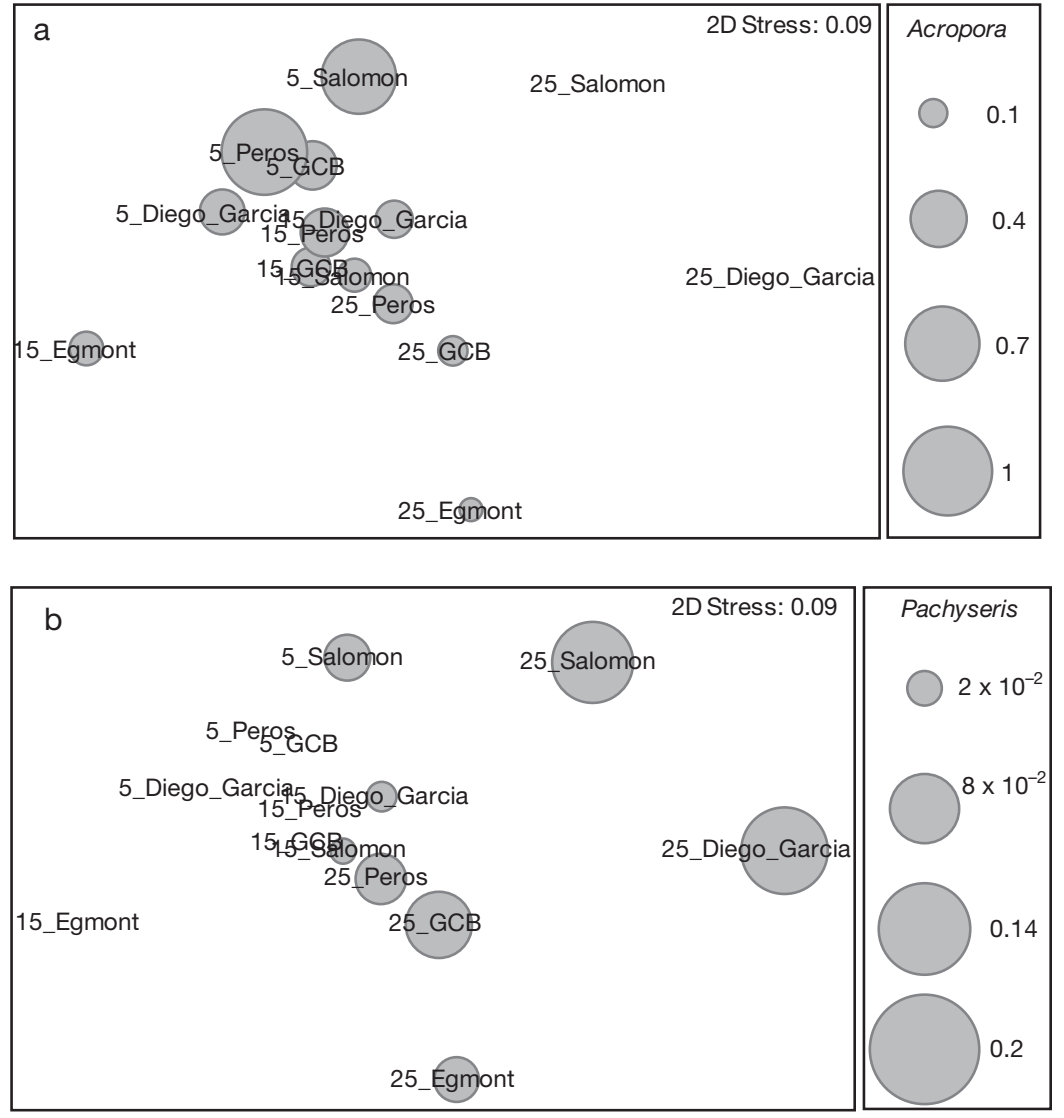

Fig. 6. Multi-dimensional scaling ordination of juveniles. Bubble plots superimposing 2 genera: (a) shallow Acropora juveniles and (b) deeper Pachyseris juveniles. Scale units are average number of juveniles of the genus per quadrat, from pooled data for each depth at each atoll
Table 3. Generic identity of juveniles in both 2001 and 2006 (data for 2001 from Sheppard et al. 2002 and S. Wilson unpubl. data). Numbers as percent of total juveniles counted. Genera are ranked according to dominance in the first year of sampling. All other genera contributed $<1 \%$ each to the total

\begin{tabular}{|lcc|}
\hline Genus & 2001 & 2006 \\
\hline Acropora & 27 & 11.5 \\
Montipora & 17 & 3.6 \\
Pavona & 12 & 25.6 \\
Faviids & 9 & 10.5 \\
Porites & 7 & 12 \\
Psammocora, Coscinaraea & 1.5 & 17 \\
Pocillopora, Stylophora & 1.5 & 5.3 \\
\hline
\end{tabular}

was onto substrates that largely lacked both coelenterates and significant macroalgae, this suggests strong depth selection at the juvenile stage by many genera. However, there is no way to distinguish whether this is itself caused by depth selection by larvae or by random settlement of larvae followed rapidly by differential post-settlement mortality at different depths.

Depth differences are illustrated further with 'bubble plots' (Fig. 6), which superimpose genus-specific hard coral juvenile density values onto an MDS (multi-dimensional scaling) plot of all sites (Bray-Curtis dissimilarity index after square-root transformation) to illustrate changes in densities of individual genera between depths. The mostly shallow Acropora and the deep Pachyseris are shown.

\section{Egmont atoll repeat mortality}

Several of these results showed Egmont atoll to have anomalously and significantly weaker recovery than other atolls. The western side had clear indications that good recovery of tabular Acropora cytherea had taken place between 5 and $10 \mathrm{~m}$ depth, but the species then was largely killed again about a year before this survey (Fig. 7). The dead A. cytherea tables (with some $A$. clathrata) were up to $120 \mathrm{~cm}$ diameter, or approximately 5 to $7 \mathrm{yr}$ old given a radial growth of $10 \mathrm{~cm} \mathrm{yr}^{-1}$ and an initial year of 'pretable' development during which colonies develop an encrusting base and then stem (Wallace 1999). The 
Table 4. Depth preferences of juveniles in 2006. First 3 columns: juveniles showing preferences for shallow, mid-, or deep sites. Fourth column: juveniles with 5 -fold difference in density between depths (most abundant depth/least abundant depth), but not fulfilling the $\chi^{2}$ requirement of no more than $20 \%$ of expected frequencies being $<5$. Porites was found almost equally at the 2 shallowest sites, but very much less at $25 \mathrm{~m}$

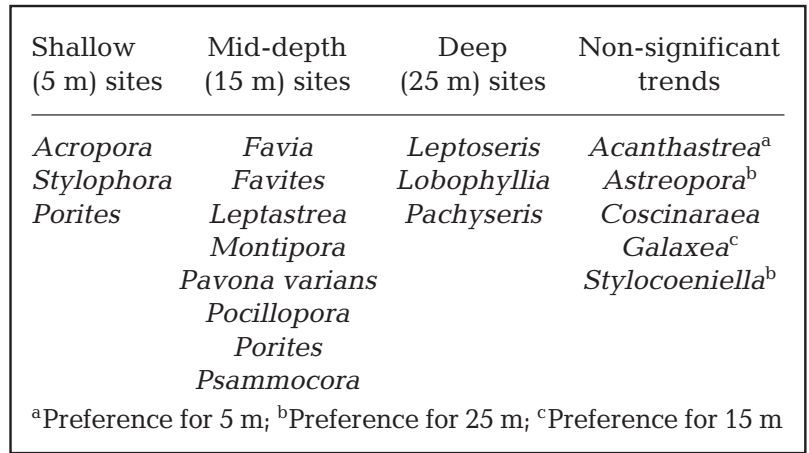

mortality affecting these corals probably occurred in 2005 (see Fig. 2). No A. cytherea colonies were seen wholly alive, although small live patches $(<5 \%$ colony area) persisted on some tables. No evidence of 'band', 'patch', or 'spot' diseases on remaining live portions were found, though swabs are being examined further (R. Jones unpubl. data). Many tables had crumbled and collapsed, and a talus layer was developing on the steeper reef slope, causing some damage to all genera in the deeper zones.

On Egmont's eastern side, in contrast, there was almost no living coral or soft coral, and no sign of recently dead table corals. The site exhibited less coral cover and fewer colonies than on the western side $(t=19$, $\mathrm{p} \leq$ $0.001 ; t=11, \mathrm{p} \leq 0.001$, respectively), and remained almost totally denuded of living coelenterates. Brief observations made at this site in 1996, 2 yr before the mass mortality, had shown 35 to $50 \%$ hard coral cover at both 5 and $10 \mathrm{~m}$ depths, with an additional $20 \%$ cover of soft coral (C. R. C. Sheppard unpubl. data). The site had no recently dead tables, and indeed no clear coral structure on the increasingly smoothed limestone surface, indicating either that there has been no recruitment to this side of the atoll, or that repeat mortalities have been frequent, preventing even rudimentary regrowth. It is this denuded eastern side more than the western side that separates this atoll from all others with respect to coral cover and colony number.

\section{DISCUSSION}

\section{Shallow zone recovery}

Patchy but strong recovery is clear, at least in shallow water, in terms of number of colonies, coral cover

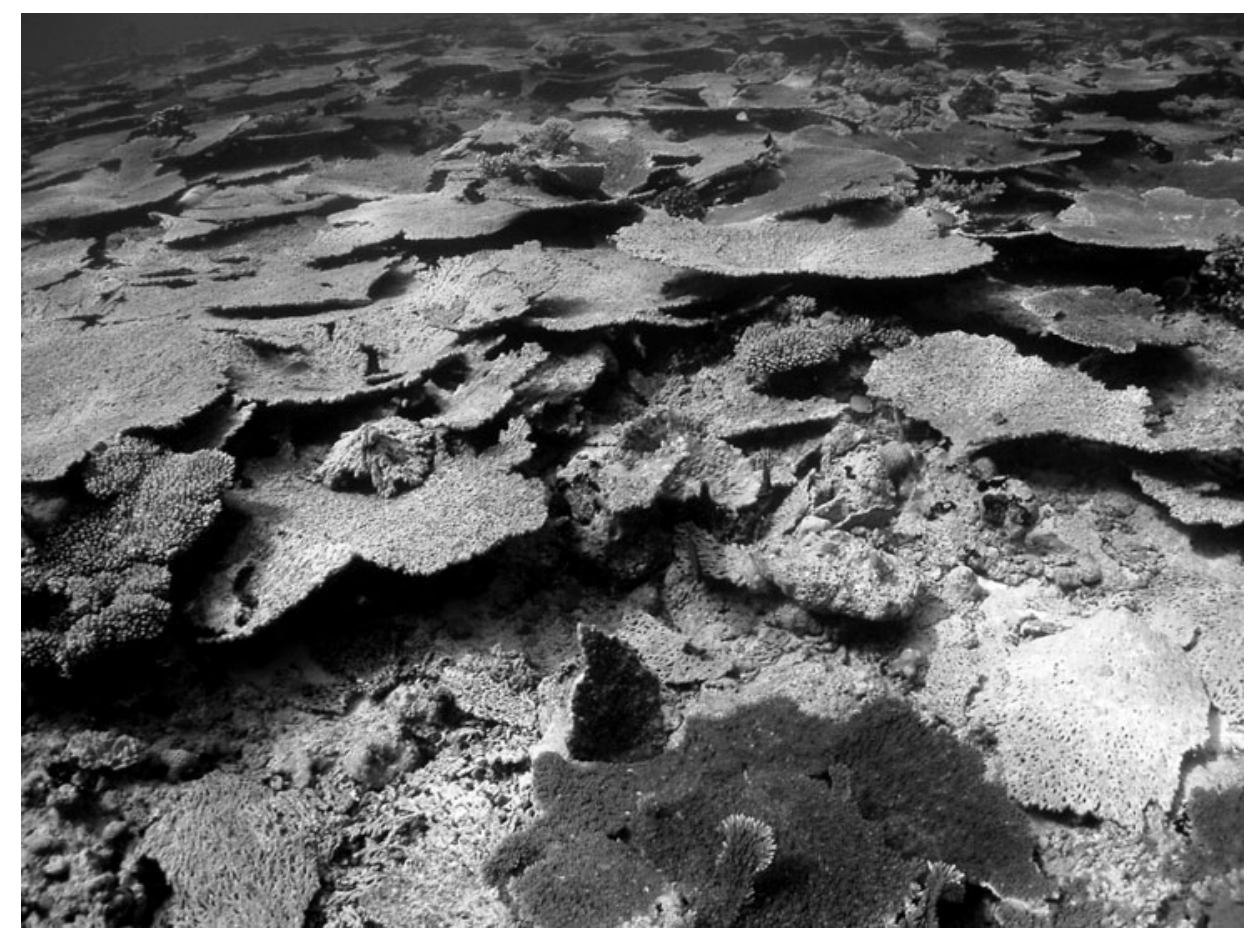

Fig. 7. Acropora cytherea. Western Egmont atoll, seaward slope at $8 \mathrm{~m}$ depth. Coral tables are mainly dead, some with living parts 
and number of recruits. However, most views of shallow (0 to $5 \mathrm{~m}$ ) seaward slopes in 2006 gave an impression of relatively depauperate coral, which is at odds with the values reported here of essentially restored coral cover at $5 \mathrm{~m}$ depth. Before 1998, seaward slopes to about $5 \mathrm{~m}$ depth were heavily dominated by mature Acropora palifera and by some A. abrotanoides that formed dense, branching stands $>1.5 \mathrm{~m}$ tall (Sheppard 1999b), while, in 2006, these species existed in the form of young colonies that were still encrusting with incipient or rudimentary branches less than about $25 \mathrm{~cm}$ tall. This 'maturity discrepancy' is commonly overlooked in many reef surveys, and cannot be accounted for in simple cover values, yet spatial complexity is important to many other species, including fishes (Graham et al. 2006). The growth rate of A. palifera is not known, but its very dense skeleton suggests much slower growth than the tabular forms. Thus, recovery of substrate cover in A. palifera zones appears to precede recovery to a mature, branching structure by perhaps 10 to $20 \mathrm{yr}$.

In contrast, at mid-depths on reef slopes (approximately 5 to $10 \mathrm{~m}$ ) several branching and tabular species have recovered their 3-dimensional complexity, although total substrate cover has recovered more slowly than in shallower water. Coral cover itself is therefore an insufficient measure of ecological condition; this has been stated before (Bellwood et al. 2004, Price et al. 2007), but cover continues to be retained in many surveys of reefs because of its simplicity compared with many alternatives.

These results and observations indicate that despite repeated warming and bleaching events, warming to lethal temperatures has not recurred in most of this archipelago. It is possible that some of the warmer years of the 2000s that caused bleaching did cause a repeat in set backs to juveniles or reproduction, but, although small colonies of 2 to $3 \mathrm{yr}$ may be readily counted, tiny but dead juveniles younger than this are often impossible to detect using visual in situ census. Further, it is not known what duration or severity of bleaching is necessary to interrupt reproduction. However, the abundance of juvenile corals at all depths on the rapidly recovering Chagos reefs, including western Egmont where a repeat of mortality of adults was observed, suggests that recruitment has not been a limiting factor across most of this archipelago. As early as 2001, a high number of juveniles was counted, although total coral cover averaged only $12 \%$ at that time. While recruitment (notably of previously dominant Acropora) has been identified as a limiting factor preventing reef recovery at marginal reef sites in east Africa (Souter \& Linden 2000), this has not been limiting here.

A number of authors have documented community shifts in post-1998 coral assemblages, such as relative increases of faviids and Porites at the expense of Acropora, notably in the more severely stressed Persian Gulf (e.g. see Riegl 2002). Changes in coral have also been accompanied by changes in associated fish composition (Berumen \& Pratchett 2006). However, no such change towards a different coral assemblage can be seen at Chagos.

Much briefer observations in the lagoons showed similarly strongly recovered dominance by Acropora (authors' unpubl. data). It has been observed previously (Sheppard 1999a) that corals in all the deep (25 to $60 \mathrm{~m}$ ) lagoons (all except Egmont, which is extremely shallow) survived considerably better than corals on seaward slopes, and it was supposed that because lagoonal corals were more regularly subjected to elevated water temperatures (Pugh \& Rayner 1981), they perhaps acclimated better to it. It can be speculated that these lagoons may be a reservoir of surviving adults that have led to such successful recruitment throughout. Sources of larvae may also include adults that had a refuge in depth on seaward slopes. Nonlocal recruitment is likely to be much slower. Upcurrent of Chagos in different seasons lies Indonesia or Africa/Seychelles, both several 1000s of kilometres distant, while the Maldives, which are closer, do not lie upcurrent in the major oceanic flows of the Indian Ocean during any season.

\section{Future trends and management}

While recovery in Chagos illustrates what is possible in 8 yr following heavy mortality, temperature projections suggest that only about $20 \mathrm{yr}$ are available before temperature peaks will occur too frequently to permit recovery (Sheppard 2003). As well as a rising mean, the 40 and 60 mo SST cycle of up to $0.8^{\circ} \mathrm{C}$ superimposed on the overall rising temperature trend (see Fig. 2) suggests that further episodes of severe warming are very likely. These cycles may be due to the Indian Ocean Dipole (Abram et al. 2007) coincident with ENSO.

Effects of global warming and local impacts such as nutrification, over-fishing, sedimentation and various forms of pollution may be synergistic, and separating effects from multiple causes is difficult and sometimes contentious (Richmond et al. 2006). Given that examples of reefs without local impacts are rare, these results illustrate the importance of reference sites such as this that lack local, direct impacts. Effective management is considering locations and kinds of reefs that can most effectively be managed (Obura 2002). In the absence of local impacts in Chagos, recovery appears to have progressed steadily at an archipelago scale, so that in the face of rising global changes that 
cannot be managed at a local level, management of those issues that can be controlled becomes increasingly important.

Acknowledgements. This research was funded in part by the UK's Overseas Territories Environment Programme and by the Government of the British Indian Ocean Territory. The authors thank A. Price for some critical comments on an earlier draft of the manuscript.

\section{LITERATURE CITED}

Abram NJ, Gagan MK, Liu Z, Hantoro WS, McCulloch MT, Suwargadi BW (2007) Seasonal characteristics of the Indian Ocean Dipole during the Holocene epoch. Nature 445:299-302

Bellwood DR, Hughes TP, Nystrom M (2004) Confronting the coral reef crisis. Nature 429:827-833

> Berumen ML, Pratchett MS (2006) Recovery without resilience: persistent disturbance and long-term shifts in the structure of fish and coral communities at Tiahura Reef, Moorea. Coral Reefs 25:647-653

Bruno JF, Selig ER (2007) Regional decline of coral cover in the Indo-pacific: timing, extent and subregional comparisons. PLoS ONE2:e711

Bryant D, Burke L, McManus J, Spalding M (1998) Reefs at risk. WRI, Washington; ICLARM, Manila; WCMC, Cambridge; UNEP, Nairobi

Clarke KR, Gorley RN (2006) PRIMER v6. Plymouth Marine Laboratory

Connell JH (1997) Disturbance and recovery of coral reefs. Coral Reefs 16:S101-S113

Gardner TA, Cote IM, Gill JA, Watkinson AR (2003) Long term region-wide declines in Caribbean corals. Science 301:958-960

Graham NAJ, Wilson SK, Jennings S, Polunin NVC, Bijoux JP, Robinson J (2006) Dynamic fragility of coral reefs. Proc Natl Acad Sci USA 103:8425-8429

Guitart C, Sheppard ALS, Frickers T, Price ARG, Readman JW (2007) Negligible risks to corals from antifouling booster biocides and triazine herbicides in coastal waters of the Chagos Archipelago. Mar Pollut Bull 54:226-232

> Hardman ER, Meunier MS, Turner JR, Lynch TL, Taylor M, Klaus R (2004) The extent of coral bleaching in Rodriguez, 2002. J Nat Hist 38:3077-3089

Hoegh-Guldberg O (1999) Climate change, coral bleaching and the future of the world's coral reefs. Mar Freshw Res 50:839-866

Hoegh-Guldberg O, Mumby PJ, Hooten AJ, Steneck RS and others (2007) Coral reefs under rapid climate change and ocean acidification. Science 318:1737-1742

> Jackson JB (1997) Reefs since Colombus. Coral Reefs 16: $\mathrm{S} 23-\mathrm{S} 32$

Jackson JBC, Kirby MX, Berger WH, Bjorndal KA and others (2001) Historical overfishing and the recent collapse of coastal ecosystems. Science 293:629-638

Knowlton N (1992) Thresholds and multiple stable states in coral reef community dynamics. Am Zool 32:674-682

McClanahan TR (2007) Response of the coral reef benthos and herbivory to fishery closure management and the 1998 ENSO disturbance. Oecologia 155:169-177

Obura DO (2002) Status of coral reefs in the Kiunga Marine National Reserve, Kenya. In: Linden O, Souter D (eds) Coral reef degradation in the Indian Ocean. Status report
2002. CORDIO, Dept of Biology and Environmental Science, Kalmar University, p 47-54

Pandolfi JM, Bradbury RH, Sala E, Hughes TP and others (2003) Global trajectories of the long-term decline of coral reef ecosystems. Science 301:955-958

Price ARG, Keeling MJ, Stewart IN (2007) A robustness metric integrating spatial and temporal information: application to coral reefs exposed to local and regional disturbance. Mar Ecol Prog Ser 331:101-108

Pugh DT, Rayner RF (1981) The tidal regimes of three Indian Ocean atolls and some ecological implications. Estuar Coast Shelf Sci 13:389-407

Purkis SJ, Riegl B (2005) Spatial and temporal dynamics of Arabian Gulf coral assemblages quantified from remote sensing and in situ monitoring data. Mar Ecol Prog Ser 287:99-113

Rayner NA, Parker DE, Horton EB, Folland CK and others (2003) Global analyses of SST, sea ice and night marine air temperature since the late nineteenth century. J Geophys Res 108(D14):4407

Richmond RH, Ostrander GK, Downs C (2006) Identifying and measuring sublethal effects of multiple stressors on corals and coral reefs. EOS Trans Am Geophys Union 87(36): OS24L-05 (abstract)

Riegl B (2002) Effects of the 1996 and 1998 positive sea-surface temperature anomalies on corals, coral diseases and fish in the Arabian Gulf (Dubai, UAE). Mar Biol 140:29-40

Roberts CM (2007) The unnatural history of the sea. Octopus Books, London

> Rogers CS, Miller J (2006) Permanent 'phase shifts' or reversible declines in coral cover? Lack of recovery of two coral reefs in St John, US Virgin Islands. Mar Ecol Prog Ser 306:103-114

Sheppard CRC (1980) Coral cover, zonation and diversity on reef slopes of Chagos atolls, and population structures of the major species. Mar Ecol Prog Ser 2:193-205

Sheppard CRC (1999a) Coral decline and weather patterns over 20 years in the Chagos Archipelago, central Indian Ocean. Ambio 28:472-478

Sheppard CRC (1999b) Changes in coral cover on reefs of Chagos over 18 years. In: Sheppard CRC, Seaward MRD (eds) Ecology of the Chagos Archipelago, Vol 2. Occasional Publications, Linnean Society, London, p 91-100

Sheppard CRC (2003) Predicted recurrences of mass coral mortality in the Indian Ocean. Nature 425:294-297

Sheppard CRC, Spalding M, Bradshaw C, Wilson S (2002) Erosion vs recovery of coral reefs after 1998 El Niño: Chagos reefs, Indian Ocean. Ambio 31:40-48

Sheppard CRC, Dixon DJ, Gourlay M, Sheppard ALS, Payet R (2005) Coral mortality increases wave energy reaching shores protected by reef flats: examples from the Seychelles. Estuar Coast Shelf Sci 64:223-234

Souter DW, Linden O (2000) The health and future of coral reef systems. Ocean Coastal Manag 43:657-688

Spalding MD, Jarvis GE (2002) The impact of the 1998 coral mortality on reef fish communities in the Seychelles. Mar Pollut Bull 44:309-321

Turner J, Klaus R (2005) Coral reefs of the Mascarenes, western Indian Ocean. Phil Trans R Soc Lond A 363:229-250

Wallace CC (1999) Staghorn corals of the world: a revision of the coral genus. CSIRO Publishing, Melbourne

Wilkinson C (ed) (2004) Status of coral reefs of the world, Vol 1 \& 2. GCRMN, Australian Inst Marine Science, Townsville

Wilson S, Fatemi SMR, Shokri MR, Claereboudt M (2002) Status of coral reef of the Persian/Arabian Gulf and Arabian Sea region. In: GCRMN report 2002, Townsville, p 7-16 